\title{
Six Sigma: concepts, tools, and applications
}

Six Sigma: concepts, tools, and applications

Mahesh S. Raisinghani

Texas Woman's University, Denton, Texas, USA

Hugh Ette, Roger Pierce, Glory Cannon and Prathima Daripaly Graduate School of Management, University of Dallas, Irving, Texas, USA

\begin{abstract}
Purpose - To provide a sound discussion on the Six Sigma methodology and see how it fits in with other quality initiatives.

Design/methodology/approach - A conceptual paper that takes at in-depth look at the origins, pros and cons of Six Sigma and how it relates to some of the other quality initiatives in industry.

Findings - The immediate goal of Six Sigma is defect reduction. Reduced defects lead to yield improvement; higher yields improve customer satisfaction. Six Sigma defect reduction is intended to lead to cost reduction. It has a process focus and aims to highlight process improvement opportunities through systematic measurement. Six Sigma implementation can have negative consequences if applied in the wrong project. Six Sigma is a toolset, not a management system and is best used in conjunction with other more comprehensive quality standards such as the Baldrige Criteria for Performance Excellence or the European Quality Award.

Research limitations/implications - This is a conceptual study and hence there are no hypotheses tested as in an empirical study. It does provide a good foundation for future research.

Practical implications - A very useful source of information and impartial advice for practitioners and researchers planning to practice the Six Sigma methodology and/or understand its pros and cons.

Originality/value - This paper fulfils an identified information/resources need for Six Sigma methodology. It is based on utilizing an extensive set of statistical and advanced mathematical tools, and a well-defined methodology that produces significant results quickly. The success of this methodology within an organization has significant momentum that can only lead to fundamental organizational cultural transformation.
\end{abstract}

Keywords Quality improvement, Quality awards, ISO 9000 series, Quality programmes

Paper type Conceptual paper

\section{Introduction}

The introduction of Six Sigma into the manufacturing arena in the early 1980s by Motorola was a step in revolutionizing the scope and use of quality systems in business today (Mayor, 2003). To define Six Sigma in simple terms is not possible because it encompasses the methodology of problem solving, and focuses on optimization and cultural change. Six Sigma accomplishes this goal by utilizing an extensive set of rigorous tools, uncompromising use of statistical and advanced mathematical tools, and a well-defined methodology that produces significant results quickly. The success of this methodology within an organization has significant momentum that can only lead to fundamental organizational cultural transformation.

The roots of sigma as a measurement standard go back to Carl Fredrick Gauss (1777-1855), who introduced the concept of the normal curve or distribution. Walter Shewhart introduced three sigma as a measurement of output variation in 1922, and stated that process intervention was needed when the output went beyond this limit.

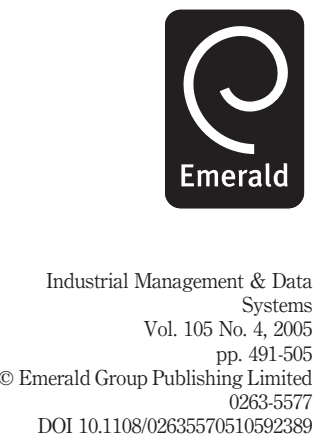


IMDS

105,4

492

The three sigma concept is related to a process yield of 99.973 per cent and represented a defect rate of 2,600 per million, which was adequate for most manufacturing organizations until the early 1980s. Two things occurred in the early 1980s that required a higher-level quality from American manufacturers. One of these was the introduction of mass produced miniature electronics, from transistor radios to televisions, which were produced in large quantities for mass-market consumption. The second and more compelling force for domestic quality improvement was the opening of global markets and subsequent introduction of Japanese electronics into foreign and American markets. The lower price and higher quality of the Japanese goods made these imports attractive to the global consumer.

In response to the threat to American manufacturing from the Japanese, several quality initiatives were introduced starting in the 1980s to help make domestic production of goods and services more competitive. "Quality Circles" at Honeywell and Fairchild Electronics was implemented to make employees aware of what was required in the output of their job by showing what their customers (i.e. the next level in the process) required. Other quality systems were introduced such as "Zero Defects" at Ford Motors, "Total Quality Management” or TQM at Boeing and Bell Telephone, and a national quality award named Malcolm Baldrige National Quality Award or MBNQA (Vokurka, 2003) was instituted to award those producers of goods and services that met the highest level of standards.

\section{The origins of Six Sigma}

Motorola was facing the same problems as the industry at this time, but found that they were losing a large portion of their business and productivity through the cost of non-quality. This includes not only the 2,600 parts per million loss in manufacturing, but lost business due to defective parts and support of systems in the field that were unreliable. Motorola's chairman at the time, Bob Galvin, decided that a much more intense effort was needed to address their problems. A Motorola engineer, Bill Smith, found that the quality level associated with a measure of Six Sigma corresponds to a failure rate of two parts per billion and adopted this as a standard. The program to achieve this lofty goal was developed at Motorola and coined "Six Sigma", which included many of the systematic and rigorous tools associated with the Six Sigma programs of today. Incidentally, "Six Sigma" is a federally registered trademark of Motorola. To illustrate why 99 per cent quality level is not acceptable, consider the following facts (McClusky, 2000; Rath and Strong, n.d.):

- at major airports, 99 per cent quality means two unsafe plane landings per day;

- in mail processing 99 per cent quality means 16,000 pieces of lost mail every hour;

- in power generation, 99 per cent quality will result in 7 hours of no electricity each month;

- in medical surgery, 99 per cent quality means 500 incorrect surgical operations per week;

- in water processing, 99 per cent quality means one hour of unsafe drinking water per month; and

- in credit cards, 99 per cent quality will result in 80 million incorrect transactions in UK each year. 


\section{The Six Sigma organization and training}

The implementation of Six Sigma in any organization is at first disruptive because it requires not only the buy in of senior management, but an active role of management in project definition and resource allocation. It also requires extensive training of some of the best people in the organization with the understanding that their role will be 100 per cent devoted to deployment of Six Sigma activities. The heart of these activities is projects that have been defined as critical paths or breakthrough goals that affect the bottom line of the organization.

The training required to implement Six Sigma involves everyone in the organization. The basic training is one day and covers process mapping, and an overview of designed experiments, hypothesis testing, metrics, and process modeling. Green belt training is more extensive, including a week of statistical analysis, SPC, and measurement systems analysis. The black belt training requires about one month of training, including ANOVA, game theory, and multivariate regression.

Workers trained in Six Sigma have been compared to internal SWAT teams, forming to tackle a specific problem and then breaking up and reforming once they achieve the desired results. The methodology applied to each problem is taken from a standard methodology, but tailored for the specific project or problem at hand. The methodology does not, fundamentally, focus on making higher quality widgets; it focuses on making the process more robust and less subject to errors. It is then applicable to areas outside of pure manufacturing organizations.

\section{Evolution of quality initiatives}

Total quality management

Total quality management (TQM) refers to a management methodology to empower organizations for self-improvement. The implementation, unlike many quality initiatives, is top down starting with upper management. The evolution of TQM incorporated a Japanese style technique called Hoshin, which defines the targets + means of any project or problem. A target statement is developed involving action(s), metrics, and a time period. Management's role is to provide the means to achieve the target. The hope for organizational cultural change is usually high as an organization tries to embrace TQM, but in many cases, it is followed by disappointment because implementation was not comprehensive enough to allow all the changes to take place. These changes are both political and personal within the organization. In some cases, leadership development for management is necessary for them to act as change agents advocating TQM. TQEM refers to TQM that emphasizes environmental controls, prevalent in industries that are associated with environmental waste, such as semiconductors and electronic component manufacturing.

\section{Quality circles}

Quality circles is a people oriented approach to quality improvement with a multi-faceted goal. The approach is to take a small group of people working on related activities and empowers them to make decisions and recommendations to improve their activities. Management's role is to provide a congenial atmosphere in which the group can make suggestions for improvement, even if it leads to management making adjustments to their style and culture. A quality circle usually involves between six and twelve people who meet voluntarily on a regular basis to identify improvements in
Six Sigma: concepts, tools, and applications

493 
IMDS 105,4

494 their areas and interactions. The benefit of this approach is that it recognizes that the people in the organization are one of the most valuable assets and attempts to tap the knowledge and insights of the employees. Organizational change due to the implementation of quality circles is a result of several aspects including fostering a change in employees attitude, development of individuals involved, creating a team spirit and positive working environment.

\section{Kaizen}

Kaizen was developed by the Japanese to overcome the inferior quality of many manufactured goods after the Second World War. The term Kai means change, and zen means good, together they stand for continuous improvement. The best way to characterize Kaizen is to think in terms of process. The western management style focuses on results and is characterized as a result oriented approach; Kaizen is a process-oriented approach and focuses on small continuous improvements.

Another key focus of Kaizen is to eliminate waste (or MUDA in Japanese). Overproduction, scrap, unnecessary motion or tasks, excessive time setting up process and breaking them down, and moving goods too frequently and too far are examples of MUDA. Some Kaizen techniques to deal with these issues are Takt time and single minute exchange of dies (SMED). Takt time is the time it takes a worker to perform his or her job function of one unit of goods. SMED refers to the teardown of a tool configuration and set up of another configuration in a different part on the same machine. Dr Shigeo Shingo was instrumental in helping the car manufacturer Toyota overcome this problem on their auto production line by using clamping mechanisms on tool heads instead of bolts. This reduced the time for re-configuring the tool from 40 minutes to around one minute. This is where the term SMED came from.

Other contributions from Dr Shingo included concepts called just in time and zero quality control. These were developed as part of a joint effort with Toyota and Mitsubishi, and later he consulted with Bridgestone, Peugeot, and AT\&T. The quality equation that he pioneered under Kaizen was Poka-Yoke techniques to correct defects + source inspections to prevent defects = Zero Quality Control.

\section{ISO9000/QS9000}

ISO9000 is not a quality system in itself, but it is a set of quality standards that are defined as being necessary for manufacturers and service organizations to be effective competitors. The standards are based on eight managerial principals that can be used by management to help their organization toward improved performance and higher quality output. The eight principals are customer focus, leadership, employee involvement, process approach to activities and resources, system approach to management, continuous improvement, and strategic supplier and customer partnerships. Experts who participate in the International Standardization Organization Technical Committee define these principals and auditing requirements. The Automotive Industry Action Group (AIAG) has taken the ISO initiative and applied it to the automotive industry as QS9000. They have made a requirement of their suppliers to become QS9000 certified (even though not all of the QS9000 criteria are relevant to other industries, such as BRV - Buzz, Rattle, and Vibration reduction). Current quality standards include ISO9001, ISO16949, OHSAS18001, and ISO13485. 
Malcolm Baldrige - MBNQA

The Malcolm Baldrige National Quality Award was established by congress in 1987 to enhance the competitiveness of American companies by seeking out best know methods as examples for others. The award is named for Mr Malcolm Baldrige, who served as Secretary of Commerce from 1981 to 1987 and is credited for making sweeping changes that improved efficiency and effectiveness of government. There are five categories that are eligible to receive this award; manufacturing, service, small business, education, and health care, although not every category receives an award every year.

There are seven categories that are assessed for excellence in the selection process. The categories are leadership, strategic planning (Bai and Lee, 2003), customer and market focus, information and analysis, human resource focus, process management and business results. These criteria have been used by thousands of organizations to improve their employee relations, improve customer satisfaction and productivity. According to the National Institute of Standards and Technology, the stock of MBNQA winners has consistently outperformed the S\&P 500 by between 2.6 and 6.5 to 1 (National Institute of Standards and Technology, 2001).

\section{Six Sigma methodologies}

\section{Measurement system analysis}

Manufacturing process produces goods that have physical characteristics that can be measured. The quality of the goods produced is based on their usefulness to the end user or customer of the products. The definition of quality has evolved to include the utility of that which is produced to the end customer. The measure of these characteristics become the first concern of a manufacturing organization that employees a Six Sigma quality system. The area responsible for determining the fitness of the measuring equipment is called measurement system analysis (MSA). The first act in utilizing a Six Sigma approach to a problem is to analyze the ability to measure the characteristics that need to be optimized.

The approach to MSA is to perform a gage study - this separates the repeatability (due to the measuring instrument) and reproducibility (due to operator bias) into separate factors. It can also determine relative accuracy between different measuring systems where there are multiple gages to measure the same output. This activity always precedes any attempts to optimize a manufacturing process to understand the accuracy of the measurements relative to the desired range of control. Once this study has been completed, the process can be experimented and the accuracy of the results can be understood.

\section{Process control}

Process control is a function in a production process that seeks to find deviations from the optimum process outputs and also uses proactive means to look for any process shifts before the product quality is compromised. Many well-documented techniques are used in this endeavor - the most obvious is the use of statistical process control (SPC). In a simple manufacturing process, the use of SPC will entail the use of control charts where the output of a given process is measured and charted. Dr Walter A. Shewart (1891-1967) is credited for the development of the control chart, where the upper and lower limits are set at \pm 3 times the standard deviation, based on
Six Sigma: concepts, tools, and applications

495 
IMDS

105,4

496 normal variation. When the process produces results outside these limits, it is said to be out of control.

Although Dr Shewart never received the recognition he deserved in his lifetime, he was responsible not only for the concepts we use in modern process control, but also the concepts that were developed by his student, W. Edward Deming based on Shewart's original "Plan, Do, Check and Act" cycle. His publications in 1931 and 1939 were the basis of the quality movement that was taken to post war reconstruction in Japan by Deming, Ishikawa, Juran, and others.

The concept of SPC and the use of control charts are not complicated, but in real world application, there are very few organizations that use and understand the concept correctly. Simply put, a product or process has specific requirements and, as explained earlier, are related to the functionality and usefulness to the end customer. These requirements are manifest in the product specifications, outside of which the product is usually rendered worthless, creating scrap. This is referred to as product control - not process control. Process control is unrelated to the product requirements, but related to the production capability. An example of this would entail running a process many times under normal conditions and measuring the output. After sufficient data are collected - at least 30 runs, but not limited to 30 - the distribution parameters are calculated. Limits are placed on the process output at the mean \pm 3 standard deviations (sigma). Subsequent runs are evaluated against these limits and not the specification limits. A measurement outside these limits indicates that something has changed or drifted in the process and the output is unusual. Actions must be taken at this point to bring the process or tool back into control. In some large manufacturing operations, the number of control charts can be as high as 100,000 and periodic checks of the control limits integrity must be preformed.

\section{Design of experiments}

When a process is being developed or has been identified as needing optimization, a technique called design of experiments (DOE) is utilized. If the process is simple and involves only one or two inputs, simple experimentation is usually sufficient. When the process is more complex, involving several inputs that may have interactions, a DOE is required to explore the relationship of the output to the inputs. An example of this is a complex manufacturing process that has inputs such as temperature, pressure, several gas flows, process speed, etc. where each can be changed independently. The outputs of a process may be dimensions, thickness of a film, resistance of a material, or any other measurable property that results from the process. The traditional experimental procedure of taking one factor at a time (OFAT) most times will not be successful in optimization due to the factor-to-factor interaction that is ignored. The DOE technique explores the operational space for all the inputs, producing results that could show non-linearity and interaction.

The output of a well-defined DOE is a mathematical process model that predicts the response of all the output variables for any combination of inputs. The rigorous treatment of a manufacturing process, including process modeling, is integral to Six Sigma methodology. Each factors' significance is quantified using analysis of variance and the resulting model is used not only to optimize the process, but to trouble shoot the process when deviations occur. 
Failure mode and effects analysis

Another quality tool used by a Six Sigma organization is the failure mode and effects analysis (FMEA) methodology. This was initially developed by the AIAG in response to poor after-market quality feedback from customers with respect to foreign competitors. This process involves gathering a representative from all the stakeholder groups, such as manufacturing, process engineering, equipment engineering, test or product engineering and a facilitator to collectively complete the FMEA. The process starts with a tool or device schematic and a process map (similar to the business process analysis). The process is carefully examined systematically to proactively determine what could possibly happen detrimental to the product at each step of the process. Depending on the severity, the possibility of occurrence and the ability to detect the failure, a relative priority number (RPN) is assigned to each activity. If the magnitude of the RPN is high, usually defined as greater than 120 (60 for a Six Sigma organization), corrective actions must be undertaken to reduce it.

A good FMEA can predict and eliminate many sources of problems before they occur. The FMEA process may identify areas that require a designed experiment for optimization or even require the purchase of new metrology equipment if the exposure to potential problems is too great. A detailed FMEA for a complex process may require a weekly meeting with five or six experts for a period of six months.

\section{Quality control and capability analysis}

After all the preventative measures are taken and corrective actions have been completed, a measure of the final quality of any process or product must be taken to insure a level of Six Sigma has been obtained. The standard measure of conformance to requirements is the process capability (Cpk). This is a quantitative measure of how much variation there is in the product or process with respect to the requirements/specifications (Table I).

The process capability is reported as an internal measure of goodness of any process or products and it is also required from key suppliers. The manufacturing organization then reports the key characteristic Cpk to their end customers. As with high RPNs from the FMEA, any parameter with a capability index less than a certain threshold requires corrective actions; for Six Sigma organizations this threshold is two.

\section{Six Sigma in service organizations}

As a quality measurement methodology, Six Sigma is also being adopted by some service industries to improve their process that results in quality customer satisfaction. While differences between small, medium, and large firms can be substantial, the differences are largely contextual in nature (Davig et al., 2003). For service industries, determining quality customer satisfaction will vary depending on the type of service that is being provided. But there are basic criteria that can be used to determine quality

\begin{tabular}{lccc}
\hline Process & Cpk & Spec range & Ppm defective \\
\hline Not capable & $<1$ & \pm 3 Sigma & 2700 \\
Capable & 1.33 & \pm 4 Sigma & 63.5 \\
Very capable & 1.67 & \pm 5 Sigma & 0.6 \\
Six Sigma & 2 & \pm 6 Sigma & 0.002
\end{tabular}

Six Sigma: concepts, tools, and applications

497 
IMDS

105,4

498 service in customer satisfaction. These include, the amount of time the customer is placed on hold, the number of times a customer calls to resolve an issue, and the knowledge and process in place available for the service representative.

Most service enterprises operate at two or three-sigma levels and with poor-quality customer experiences. Six Sigma's goal is to reduce the amount of bad customer experience to three in a million (for Six-Sigma level). Six Sigma methodologies are used to obtain factual information regarding customer satisfaction. This follows the method of define, measure, analyze, improve, and control (DMAIC). By defining, measuring, analyzing and controlling each process, service organizations can gauge the root cause of the problem. Defining and measuring the problem, opportunity, and process involves doing some business process analysis. This will enable the organization to map the process and specify customer requirement.

Analysis of the business process determines where the organization fails to measure up to customer expectations. This process involves more detailed evaluation of the data gathered. This will enable the organization to understand the cause of the problem. In the case of Texas Instrument's Defense Systems and Electronics Group, customers were asked to give the company a rating on a ten-point scale on a list of 32 attributes related to service quality, product performance, field-service representatives, and company image, as compared to its competitors.

To improve quality in customer satisfaction, it is important that the measurement being used is something that can also be measured against the competitor. The results are then analyzed and used to either improve upon the process or leave it as it is. By knowing the root cause of the problem, organizations can then come up with different alternatives for improvements (Getty and Prybutok, 2003; Montes et al., 2003). Once an improvement method is selected, controlling the process takes place. It is important that the process is constantly monitored to verify its consistency.

\section{Case studies}

Motorola's application of Six Sigma

Six Sigma became a poster child for driving down cost and improving organizational bottom line when Motorola won the Malcolm Baldrige National Quality Award in 1988, which was the first year this award was presented. In 1987, Motorola was operating at a four sigma level. This means that Motorola was running at defect rate of about 6,200 per million opportunities compared to its Japanese counterparts that were running at 3.4 defects per million opportunities. Motorola's defect rates lead to increase cost to sales and diminished profits and contributed to losing market share. Motorola's customers included many police, fire, and emergency response organizations that relied on radios and communication equipments manufactured by Motorola. Losing these customers's to foreign competition would be public relations and financial disaster for Motorola. Table II illustrates the impact of sigma or quality level to product sales which ultimately impacts profit margin.

Given Motorola's dire situation, Chairman Bob Galvin mandated bold initiative for the company. This mandate could be summed up as:

(1) improve product quality by ten times in two years;

(2) improve product quality by 100 times in four years; and

(3) reach Six Sigma quality level in five years. 
The immediate goal of Six Sigma is to reduce defects. Reducing defects leads to yield improvement. Higher yields improve customer satisfaction. The ultimate goal is enhanced net income. Motorola's focus on drastically reducing defects to the 3.4 DPMO level was quantified in dollar terms at $\$ 2$ billion over a four-year period (McClusky, 2000).

One area that Motorola's applied Six Sigma principles was the redesigned and manufacturing of its pagers in 1990. Pagers were new technology in 1990 and Motorola's pagers were highly priced - about $\$ 1,500$ - and took an average about 18 months to product. This process was redesign with Six Sigma principles with dramatic improvements. The production lead time went from 18 months to just about 72 minutes and cost went from $\$ 1,500$ to just around $\$ 200$ (McClusky, 2000). Information Technical, which heavily slanted toward services, time and material charges, the company, experienced 40 percent productivity improvements. Six Sigma applications brought process focus to the company and resulted in tremendous cost and process improvements. In 2002, Six Sigma application earned Motorola another Malcolm Baldrige National Quality Award in the Government and Industrial Sector.

\section{Allied signal's application of Six Sigma}

American corporations, in general, will always take notice of things or processes that can demonstrate measurable results in a short amount of time. This was the case with Six Sigma principles. With the documented productivity and process improvements by Motorola, boardroom executives were captivated with this new process known as Six Sigma. One of these was Larry Bossidy, CEO of Allied Signal. Allied Signal, a technology and manufacturing company, applied Six Sigma principles in the 1990s to design and recertification of aircraft engines. The redesign and certification of aircraft engine was reduced from 42 to 33 months (Schwalbe, 2004). The company also started implementing Six Sigma principles in most of its quality improvement processes. The company attributes Six Sigma applications to saving the organization more than $\$ 600$ million a year by 1999. Six Sigma teams were accounted for dramatic defects reductions and improvement in design or redesign of new processes. Allied was able to reach these improvements because Six Sigma relies on capable processes that do not minimize defects coupled with disciplined approach to gather and analyze data and benchmark against the best in the world. As one of the company's director said, "Six Sigma changed the way we think and the way we communicate. We never used to talk about the process or the customer; now they are part of our everyday conversation" (Schwalbe, 2004).

\begin{tabular}{lccc}
\hline Sigma level & Defects per million opp. & Quality level (per cent) & Cost as per cent of sales \\
\hline 1 & 691,000 & 31.00 & $>40$ \\
2 & 309,000 & 69.00 & $20-40$ \\
3 & 67,000 & 93.30 & $15-30$ \\
4 & 6,200 & 99.40 & $10-20$ \\
5 & 230 & 99.98 & $5-10$ \\
6 & 3.40 & 99.9997 & $0-5$
\end{tabular}

Source: The rise, fall and revival of Six Sigma quality (McClusky, 2000)

\section{Six Sigma: concepts, tools, and applications}

499

\section{9}


IMDS

105,4

500
GE's application of Six Sigma

After Motorola publicized the success of Six Sigma in 1995 and garnished believers like Larry Bossidy of Allied Signal, Jack Welch, CEO of GE signed on to this new quality initiative and has been widely credited wide ranging applications of Six Sigma principles. In 1995, Jack Welch asked Larry Bossidy to address GE audience at the 1995 management meeting. His topic was Six Sigma and how it dramatically improved Allied Signal's bottom line and processes. Welch signed on to Six Sigma from that point and made it a crusade for GE under his leadership. GE Six Sigma initiatives included product globalizations, product services, and electronic commerce. These initiatives complemented and extended each other and resulted in compound savings in process improvements and cost (GE Annual Report, 1997). All operating and divisional managers were tasked with implementing Six Sigma in their respective organizations. Jack Welch took personal interest and often sits in on meetings and on presentations regarding Six Sigma to monitor implementations and improvements.

In his book Straight from the Gut, Jack claims that by 1998, GE had generated $\$ 750$ million savings over and above their investments in Six Sigma. Mr Welch went on to say that the expected saving for 1999 was $\$ 1.5$ billion, and attributed operating margin improvement from 14.8 per cent in 1996 to 18.9 per cent in 2000 to the application of Six Sigma by GE. GE Plastics, with 30 plants worldwide, achieved 3 per cent compounded productivity improvements each year, effectively bring one new plant online annually, with no capital outlay. In 1999, GE Annual Report highlighted $\$ 2$ billion in benefits and set the company's sites on more improvement for the future.

Our Lady of Lourdes application of Six Sigma

Our Lady of Lourdes Regional Medical Center, located in Lafayette, Louisiana implemented Six Sigma to resolve hospital bed availability delays (Sager and Ling, n.d.). This hospital chose GE Medical Systems to implement a Six Sigma program as a method of achieving quality and process improvements. Using the Six Sigma's DMAIC process, the team set out to define the various criteria for process improvement.

Defining the problem. For this project, an opportunity was the time from a written discharge order to the time the bed is available for the next patient. A defect is any opportunity exceeding the upper specification limit or maximum allowable time to complete that process. The project team included 15-member cross-functional team from Lourdes, along with a team from GE Medical Systems. The teams participated in several sessions to outline the current discharge to bed availability processes and the associated "critical to quality" elements. follows:

Measuring the phases. The project team divided up the processes into sub process as

- doctor writes discharge order until patient leaves room;

- patient leaves room until housekeeping notified;

- housekeeping notified until housekeeping starts cleaning; and

- housekeeping starts cleaning until housekeeping finishes cleaning.

Three nursing units representing approximately one-third of the total beds were measured and used as a statistically significant sample for the entire hospital. Time targets and upper specification limits were set for each of the four sub-processes based 
on the experience of the project team experiences and customer's expectation. The team's reports indicated that 60 per cent of the time, "discharge to bed available" process took longer than the upper spec limit. The team then created a summary of key findings, enumerating why the process takes longer and the variances within the processes.

Analyzing the data. The team created a fishbone to visually map the drivers of variability in the process. The team created payoff matrix to chart each driver of variability on an "Effort to Fix" vs "Benefit from Fixing" axis. The team measured all the steps and correlated this with the process lengths, and determined priorities based on which drivers had the greatest impact.

A thorough stakeholder analysis was conducted to ensure that the targeted processes would be effectively changed. Specific strategies were formulated for each stakeholder to ensure the group was prepared for and supportive of changes to the current processes. Stakeholder Analysis shown in Table III.

Improving the process. After uncovering the root causes and prioritizing desired actions to improve the processes, the team agreed on the following actionable items.

- To add priority for "pending discharge" on the computer that listed patients needing an X-ray, lab work, or supplies/equipment at home. This ensured that a patient needed additional services before discharge was attended to in a timely manner.

- Educating the staff on the purpose and use of the bed tracking system to ensure communicating room vacancy in a timely manner. This ensured that Bed Control was aware and could process the bed for the next patient.

- Adding a question to the core data sheet to obtain patience's means of getting home and not allow this to be a factor at the last minute.

\begin{tabular}{|c|c|c|}
\hline Stakeholder & Issues/concerns & Influence strategy \\
\hline Medical doctors (MDs) & Do not like to be told what to do & $\begin{array}{l}\text { Make it seem as if it is their idea; } \\
\text { improve MD and patient } \\
\text { satisfaction in discharge and admit } \\
\text { of next patient; save MD time; Drs } \\
\text { Ritchey and St Clergy present to } \\
\text { MDs }\end{array}$ \\
\hline Nurses/nurse assistants & $\begin{array}{l}\text { Extra work - get new patient but } \\
\text { no incentive }\end{array}$ & $\begin{array}{l}\text { If shorten turn over time within } \\
\text { measurable time period receive an } \\
\text { incentive; have someone help with } \\
\text { admitting process }\end{array}$ \\
\hline Unit secretary & $\begin{array}{l}\text { Additional work that has to be } \\
\text { done }\end{array}$ & $\begin{array}{l}\text { At high admit/discharge times } \\
\text { have additional help; Incentive if } \\
\text { they do a good job }\end{array}$ \\
\hline Dietary & Additional workload & $\begin{array}{l}\text { Communicate dirty dishes will be } \\
\text { returned sooner, cleaned earlier, } \\
\text { and able to leave sooner; Won't } \\
\text { have to make up additional meal } \\
\text { trays if patient discharged }\end{array}$ \\
\hline
\end{tabular}

Source: Leveraging Six Sigma to improve hospital bed availability (Sager and Ling, n.d.)

Table III.

Stakeholders analysis for hospital availability project 
IMDS

105,4

502
- Creating patient discharge for patients and family members to watch so that discharge expectations are communicated early in their hospital stay.

- To initiate nursing home patients discharge process at 24 hours prior to discharge by physician to enable efficient process since these patients often require more time.

Overall, the time from discharge order to bed available was reduced from 267 to 235 minutes, a 12 per cent decrease. The variability of the process also improved. The standard deviation went from 318 to 168 minutes. The potential one-year economic impact of the improved process for the sample units was about $\$ 66,000$. If this process improvement were instituted enterprise-wide, the impact would be $\$ 198,000$ annually.

Controlling the process. As part of its controls, the project team implemented a "dashboard" to track results and ensure the improved process remains improved over the long haul. Leadership used the dashboard to monitor progress and take appropriate steps in a timely manner.

\section{Arguments against Six Sigma}

What causes some companies to succeed in their change program? According to Jerome A. Blakeslee, a director at PricewaterhouseCoopers Consulting, the first principle is: "Successful Six Sigma implementation efforts are driven by committed leaders with edge". Noel Tichy and Eli Cohen in "The Leadership Engine" describe "edge" as the ability of top leaders to make tough decisions effecting the long-term success of their businesses, challenge conventional thinking, and sometimes recommend unpopular or unusual ideas as part of focusing the organization on needed change. The second principle recommended by Blakeslee is that Six Sigma efforts must be integrated with existing initiatives, business strategy, and key performance measures.

Companies beginning Six Sigma simply because they feel they ought to face sub-optimization if it is not linked with other key efforts. Digital Equipment Corporation, in early 1990s, instituted Six Sigma in many plants, service groups, and support functions around the world. When an influx of newcomers occurred in any of these organizations, the proponents of Six Sigma were back to the sales role of convincing the new arrivals of the Six Sigma payback for the company and its customers. They failed to articulate the critical business need for change and failed to develop and nurture the key leaders to support the Six Sigma program. Six Sigma never became fully integrated into the business practices and was never leveraged with other programs, so it eventually withered away.

Many companies such as Clarke American have chosen not to go the Six Sigma route since they have been on a 15 year journey of quality improvement and have achieved great results through their focus on customer satisfaction and employee involvement. A walk around their offices shows every department with numerous scorecards that are posted and used monthly. A top manager at Clarke American described a tour of a GE plant where management fully embraced Six Sigma as missing a focus on inventory with all the disadvantages that improper inventory management can have on organizational operational efficiencies. Six Sigma's focus is not on inventory movements or management, but rather on processes that may involve those inventories. 
Stamatis (2000) asserts that Six Sigma is just "an appraisal tool that does nothing for presentation". The key argument is that quality needs to be integrated into the design, and to not just create methods to monitor them at the manufacturing level. This argument is in line with Genichi Taguchi, best known for developing the Taguchi methods for optimizing processes. The key concepts in the Taguchi model were that quality should be designed into the products and not inspected into it. Taguchi invented the robust design methodology that focus on eliminating defects by substituting scientific inquiry in place of trial and error methods. Stamatis (2000) argued that organizational culture needs to put quality into planning and drive quality throughout the entire organization. He believes that Six Sigma is being used as a "marketing ploy" since it offers easy money to quality consultants who are inconsistent in their material content and knowledge base. He states that Six Sigma reformulates the quality operating system introduced by Ford Motor Company in the early 1990s. The Ford system included advanced product quality planning (APQP), problem solving and SPC. The APQP method alone, Stamatis believes to be superior to Six Sigma, with the politics of the organization being the major contributing factor to success in lieu of the Six Sigma method.

Keen (1997) takes issue with the typical Six Sigma approach of jumping into processes and projects without fully understanding where the real benefits are for the organization. He contends that the definition of processes for each firm yields unique answers and it takes time to identify them through a course of discovery. He classifies processes according to five levels of salience: identify, priority, background, mandated and folklore. These processes then need to be evaluated to determine how much economic worth they provide to the firm. The results of these analyses yield processes upon which to focus.

Schneiderman (1999) states that he does not like Six Sigma because "It's neither simple to understand nor, in most applications, an effective proxy for customer satisfaction. Its definition is ambiguous and therefore easily gamed because there is no accepted test for what to include as an 'opportunity' for a defect". Challenging the well-publicized billions of dollars in claimed savings, states: "I'd really like to see an independent audit so that I could understand the basic assumptions used. I would hope that the calculated savings net out the component of traditional cost reduction, as captured, for example, by the historical cost experience curve. . I've been told of more than one case where a product defect has been dropped from the calculation with the justification that 'we can't be measured on what we don't control"'.

Schneiderman (1999) also notes that opportunities are not weighted by importance to the customer in Six Sigma. He explains that ten unimportant defects might improve while five important ones get worse. In that case the sigma metric would improve, but customer satisfaction goes down. Schneiderman advises: "Use Six Sigma as the name for your version of TQM, but don't track its numerical value or put it on your balanced scorecard".

\section{Conclusion}

Six Sigma rose to national prominence when Motorola won the Malcolm Baldrige National Quality Award in 1988, the first year of the award. Motorola's documented productivity improvement and financial success spurned many followers of well-known organizations as Allied Signal and GE. GE, under Jack Welch,
Six Sigma: concepts, tools, and applications

503 
IMDS

105,4

504 implemented Six Sigma in many of its processes and documented significant gains in process and financial results. The immediate goal of Six Sigma is defect reduction. Reduced defects lead to yield improvement; higher yields improve customer satisfaction. The ultimate goal is enhanced net income. The dollars saved are often the attention getter for senior executives. Many companies, such as Clark America, have chosen not to go the Six Sigma route. Six Sigma implementation can have negative consequences if applied in the wrong project. It has a process focus and aims to highlight process improvement opportunities through systematic measurement. Six Sigma defect reduction is intended to lead to cost reduction. Six Sigma is a toolset, not a management system and is best used in conjunction with other more comprehensive quality standards such as the Baldrige Criteria for Performance Excellence or the European Quality Award.

\section{References}

Bai, R-J. and Lee, G-G. (2003), "Organizational factors influencing the quality of the IS/IT strategic planning process", Industrial Management \& Data Systems, Vol. 103 Nos 8/9, p. 622.

Davig, W., Brown, S., Friel, T. and Tabibzadeh, K. (2003), "Quality management in small manufacturing”, Industrial Management \& Data Systems, Vol. 103 Nos 1/2, pp. 68-78.

General Electric Annual Report (1997), "Letter to our share owners", available at: www.ge.nl/ annual97/share/index.html (accessed 28 January 2004).

Getty, R.L. and Prybutok, V.R. (2003), "The effects of streamlined operations on the perceived quality success criteria at Lockheed Martin Aeronautics - Fort Worth", Industrial Management \& Data Systems, Vol. 103 Nos 1/2, pp. 85-97.

Keen, P.G.W. (1997), The Process Edge: Creating Value where it Counts, Harvard Business School Press, Boston, MA.

McClusky, B. (2000), "The rise, fall and revival of Six Sigma quality: measuring business excellence", The Journal of Business Performance Measurement, Vol. 4 No. 2, Second Quarter 2000.

Mayor, T. (2003), "Six Sigma comes to IT: targeting perfection”, CIO Magazine, available at: www.cio.com/archive (accessed 24 January 2004).

Montes, F.J.L., Moreno, A.R. and Molina, L.M. (2003), “An analysis of the relationship between quality and perceived innovation: the case of financial firms", Industrial Management \& Data Systems, Vol. 103 Nos 8/9, p. 579.

National Institute of Standards and Technology (2001), "Baldrige index stock study 2001", iSix Sigma, available at: www.isixsigma.com/library/content/c010426a.asp (accessed 30 January 2004).

Rath and Strong Management Consultants (n.d.), "Six Sigma", available at: www.rathstrong. $\mathrm{com} / \mathrm{rs} /$ pbuild/linkbuilder.cfm?selection $=\operatorname{dn} 9.9 .12$ (accessed 25 January, 2004).

Sager, R. and Ling, E. (n.d.), "Leveraging Six Sigma to improve hospital bed availability", available at: www.isixsigma.com/library/content/c030708a.asp (accessed 11 January 2004).

Schneiderman, A.W. (1999), "Q. when is Six Sigma not Six Sigma? A: when it's the Six Sigma metric!”, available at: www.schneiderman.com (accessed 15 January 2004).

Schwalbe, K. (2004), Information Technology Project Management, 3rd ed., Thomson Learning Course Technology, Park City, UT, pp. 275-82. 
Stamatis, D.H. (2000), "Who needs Six Sigma anyway?", Quality Digest e-Store, available at: www.qualitydigest.com/may00/html/sixsigmacon.html (accessed 30 January 2004).

Vokurka, R.J. (2003), "Using the Baldrige criteria for personal quality improvement”, Industrial Management \& Data Systems, Vol. 101 No. 7, pp. 363-70.

Six Sigma: concepts, tools, and applications

\section{Further reading}

Blakeslee, J.A. Jr (1999), “Achieving quantum leaps in quality and competitiveness: implementing the Six Sigma solution in your company", ASQ's 53rd Annual Quality Congress Proceedings, May.

Bonsignore, M.R. (1999), "Keynote address”, paper presented at Quality New Jersey Conference, 6 December, available at: www.honeywell.com/about/pagel5_3.html (accessed 24 January 2004).

Dusharme, D. (2004), “Six Sigma Survey: Big Success. . But What About the other 98 percent?”, February, available at: www.qualitydigest.com/feb03/articles/01_article.shtml (accessed 9 February 2004).

Fortenot, G., Behara, R. and Gresham, A. (1994), "Six Sigma in customer satisfaction”, Quality Progress, Vol. 27 No. 12, pp. 73-8.

Harry, M. and Schroeder, R. (1999), Six Sigma: The Breakthrough Management Strategy Revolutionizing the World's Top Corporations, Doubleday, New York, NY.

Latzko, W.J. (1995), Notes on the Six Sigma Concept.

Pyzdek, T. (n.d.), The Six Sigma Revolution, available at: www.qualityamerica.com/ knowledgecente/articles/pyzdeksixsig (accessed 30 January 2004).

Shankar, S.J. (2000), “Using Six Sigma for growth”, New Straits Times, 28 March.

Way, P. IV (2000), "Honeywell posts record first quarter earnings", Defense Daily, 14 April, pp. 14-19. 